\section{Case Reports in Dermatology}

\title{
Bazex Syndrome in Lung Squamous Cell Carcinoma: High Expression of Epidermal Growth Factor Receptor in Lesional Keratinocytes with Th2 Immune Shift
}

\author{
Maki Amano ${ }^{a}$ Takaaki Hanafusa $^{a} \quad$ Sakiko Chikazawa ${ }^{a} \quad$ Makiko Ueno $^{a}$

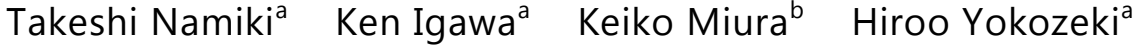 \\ ${ }^{a}$ Department of Dermatology, Graduate School of Medical and Dental Sciences, Tokyo \\ Medical and Dental University, Tokyo, Japan; ${ }^{b}$ Department of Pathology, Graduate School \\ of Medical and Dental Sciences, Tokyo Medical and Dental University, Tokyo, Japan
}

\section{Keywords}

Bazex syndrome $\cdot$ Erythroderma $\cdot$ Paraneoplastic syndrome

\begin{abstract}
An 82-year-old Japanese man was referred for detailed examination of hyperkeratotic erythematous plaques on his palms and soles for 6 months. Two weeks before his first visit, he had undergone lung lobectomy for right lung squamous cell carcinoma (SCC). Laboratory findings showed elevations of eosinophil counts, serum IgE, thymus and activation-regulated chemokine, SCC antigen, and soluble interleukin-2 receptor levels. Histological results of a skin biopsy involving the left palm showed psoriasiform dermatitis. Before lung lobectomy, the hyperkeratotic erythematous plaques on the palms and soles and the erythemas on the trunk and extremities were difficult to treat with topical steroids. After lobectomy, the skin symptoms dramatically and rapidly subsided with topical steroids. Therefore, we diagnosed Bazex syndrome (BS), also known as acrokeratosis paraneoplastica, as a paraneoplastic cutaneous disease in lung SCC. The mild eosinophilia subsided and levels of SCC antigen, IgE,
\end{abstract}




\section{Case Reports in Dermatology}

and soluble interleukin-2 receptor were reduced. BS is a paraneoplastic cutaneous disease characterized by acral psoriasiform lesions associated with an underlying neoplasm. In a previous report, a shift to the Th2 immune condition was found in patients with non-small cell lung cancer, as shown in our patient. Epidermal growth factor receptor (EGFR) is also known as tumor growth factor- $\alpha$ receptor; it is increased in psoriatic keratinocytes. In our case, EGFR expression increased in lesional keratinocytes 2 weeks after surgery and decreased 4 weeks after surgery. We speculate that a shift to Th2 immune reactions in lung SCC may be the pathogenesis of BS, whereby lesional keratinocytes highly express EGFR in parallel with disease activity.

An 82-year-old Japanese man was referred for detailed examination of hyperkeratotic erythematous plaques on his hands (palms) and feet (soles) for 6 months. Two weeks before his first visit, he had undergone lung lobectomy for right lung squamous cell carcinoma (SCC). He had a history of tongue and gastric cancer, both of which were in remission. On admission, he had hyperkeratotic erythematous plaques on his palms and soles (Fig. 1). Multiple itchy, coalescing, scaly, papular erythemas, $20 \mathrm{~mm}$ in diameter, were on his trunk and extremities but did not cover more than $90 \%$ of his entire body surface area, which is the definition of erythroderma. Transverse abdominal folds were not spared, indicating that the "deck chair" sign characteristic of papuloerythroderma of Ofuji was negative. Laboratory findings were as follows: white blood cell count, $9.4 \times 10^{3} / \mu \mathrm{L}$ (normal range, 3.6-9.3 $\times$ $10^{3} / \mathrm{L}$ ); eosinophils, 9.4\%, $8.3 \times 10^{2} / \mu \mathrm{L}$ (normal range, $0.6-8.0 \%$ ); hemoglobin, $12.6 \mathrm{~g} / \mathrm{dL}$ (normal range, $13.8-16.9 \mathrm{~g} / \mathrm{dL}$ ); C-reactive protein, $0.11 \mathrm{mg} / \mathrm{L}$ (normal range, $0.0-0.2$ $\mathrm{mg} / \mathrm{L}$ ); creatinine, $0.74 \mathrm{mg} / \mathrm{dL}$ (normal range, $0.7-1.1 \mathrm{mg} / \mathrm{dL}$ ); alanine aminotransferase, 17 U/L (normal range, 8-48 U/L); IgE, 4,686 IU/mL (normal level, <295 IU/mL); thymus and activation-regulated chemokine (TARC), 3,984 pg/mL (normal level, $450 \mathrm{pg} / \mathrm{mL}$ ); SCC antigen, $15.4 \mathrm{ng} / \mathrm{mL}$ (normal level, $<1.5 \mathrm{ng} / \mathrm{mL}$ ); and soluble interleukin-2 receptor, $1,050 \mathrm{U} / \mathrm{mL}$ (normal range, 145-519 U/mL). His Brinkman index score was 1,600 and he stopped smoking after the diagnosis of lung cancer. Histological results of a skin biopsy involving the left palm revealed parakeratosis, acanthosis, elongated rete ridges, and perivascular lymphocyte infiltration in the upper dermis. The granular layer remained and exocytosis of lymphocytes was found (Fig. 2a, b). Biopsy involving erythema of the left forearm revealed an eczematous reaction. Contrast-enhanced computed tomography did not detect additional internal malignancies. Before lung lobectomy, the hyperkeratotic erythematous plaques on the palms and soles and the erythemas on the trunk and extremities were difficult to treat with topical steroids. After lobectomy, the skin symptoms dramatically and rapidly subsided with topical steroids. There was no history of palmoplantar keratosis. Potassium hydroxide preparation and microscopic examination of the soles did not reveal any tinea infection. No drugs were suspected of causing adverse cutaneous reactions. Therefore, we diagnosed Bazex syndrome (BS), also known as acrokeratosis paraneoplastica, as a paraneoplastic cutaneous disease in lung SCC. Mild eosinophilia and elevated SCC antigen, IgE, and soluble interleukin-2 receptor levels improved to $8.9 \%\left(4.8 \times 10^{2} / \mu \mathrm{L}\right), 13.2 \mathrm{ng} / \mathrm{mL}, 1,957 \mathrm{U} / \mathrm{mL}$, and $486 \mathrm{U} / \mathrm{mL}$, respectively; however, elevated serum TARC levels remained as high as $4,277 \mathrm{pg} / \mathrm{mL} 6$ months after lung lobectomy.

BS is a paraneoplastic cutaneous disease characterized by acral psoriasiform lesions associated with an underlying neoplasm. The skin of the palms and soles initially thickens when the neoplasm is not active. Subsequently, the trunk and extremities become involved, as shown in our patient $[1,2]$. The pathogenesis of BS is unknown, but some immunological 
mechanisms are hypothesized and serum levels of SCC antigen can parallel the severity of cutaneous lesions [3]; however, they can also parallel the severity of the primary malignancy as a tumor marker. In a previous report, a shift to the Th2 immune condition was found in patients with non-small cell lung cancer. Radical surgery treatment may improve the Th1/Th2 shift in patients [4], as shown in our patient, who had an eczematous reaction on the extremities and trunk with the increased serum IgE and TARC and increased eosinophil count. Serum IgE level and eosinophil count were decreased after surgery. Cigarette smoking increases some inflammation markers, including TARC [5]. Epidermal growth factor receptor (EGFR) is also known as tumor growth factor- $\alpha$ receptor; it is increased in psoriatic keratinocytes [6] and decreased in atopic dermatitis (AD) keratinocytes [7]. We compared the expression of EGFR in lesional keratinocytes between 2 and 4 weeks after lobectomy. Surprisingly, its expression was increased in lesional keratinocytes of the left palm 2 weeks after surgery and decreased in those of the left sole 4 weeks after surgery (Fig. 2c, d). From these results, we speculate that a shift to Th2 immune reactions in lung SCC, which is similar to that in $\mathrm{AD}$ patients, may be the pathogenesis of acral psoriasiform lesions in $\mathrm{BS}$, whereby lesional keratinocytes highly express EGFR in parallel with disease activity; however, it is usually suppressed in AD patients.

\section{Statement of Ethics}

The authors have no ethical conflicts to disclose.

\section{Disclosure Statement}

The authors have no conflicts of interest to disclose.

\section{References}

1 Bazex A, Griffiths A: Acrokeratosis paraneoplastica - a new cutaneous marker of malignancy. Br J Dermatol 1980;103:301-306.

2 Valdivielso M, Longo I, Suarez R, Huerta M, Lazaro P: Acrokeratosis paraneoplastica: Bazex syndrome. J Eur Acad Dermatol Venereol 2005;19:340-344.

3 Hara M, Hunayama M, Aiba S, Suetake T, Watanabe M, Tanaka M, Tagami H: Acrokeratosis paraneoplastica (Bazex syndrome) associated with primary cutaneous squamous cell carcinoma of the lower leg, vitiligo and alopecia areata. Br J Dermatol 1995;133:121-124.

- 4 Li J, Wang Z, Mao K, Guo X: Clinical significance of serum T helper 1/T helper 2 cytokine shift in patients with non-small cell lung cancer. Oncol Lett 2014;8:1682-1686.

-5 Shiels MS, Katki HA, Freedman ND, Purdue MP, Wentzensen N, Trabert B, Kitahara CM, Furr M, Li Y, Kemp TJ, Goedert JJ, Chang CM, Engels EA, Caporaso NE, Pinto LA, Hildesheim A, Chaturvedi AK: Cigarette smoking and variations in systemic immune and inflammation markers. J Natl Cancer Inst 2014;106:dju294.

-6 Krueger JG, Krane JF, Carter DM, Gottlieb AB: Role of growth factors, cytokines, and their receptors in the pathogenesis of psoriasis. J Invest Dermatol 1990;94:135S-140S.

7 Saaf A, Pivarcsi A, Winge MC, Wahlgren CF, Homey B, Nordenskjold M, Tengvall-Linder M, Bradley M: Characterization of EGFR and ErbB2 expression in atopic dermatitis patients. Arch Dermatol Res 2012;304:773-780. 


\section{Case Reports in Dermatology}

\begin{tabular}{l|l}
\hline Case Rep Dermatol 2016;8:358-362 \\
\hline DOI: 10.1159/000452827 & $\begin{array}{l}\text { C 2016 The Author(s). Published by S. Karger AG, Basel } \\
\text { www.karger.com/cde }\end{array}$ \\
\hline
\end{tabular}

Amano et al: Bazex Syndrome in Lung Squamous Cell Carcinoma: High Expression of Epidermal Growth Factor Receptor in Lesional Keratinocytes with Th2 Immune Shift

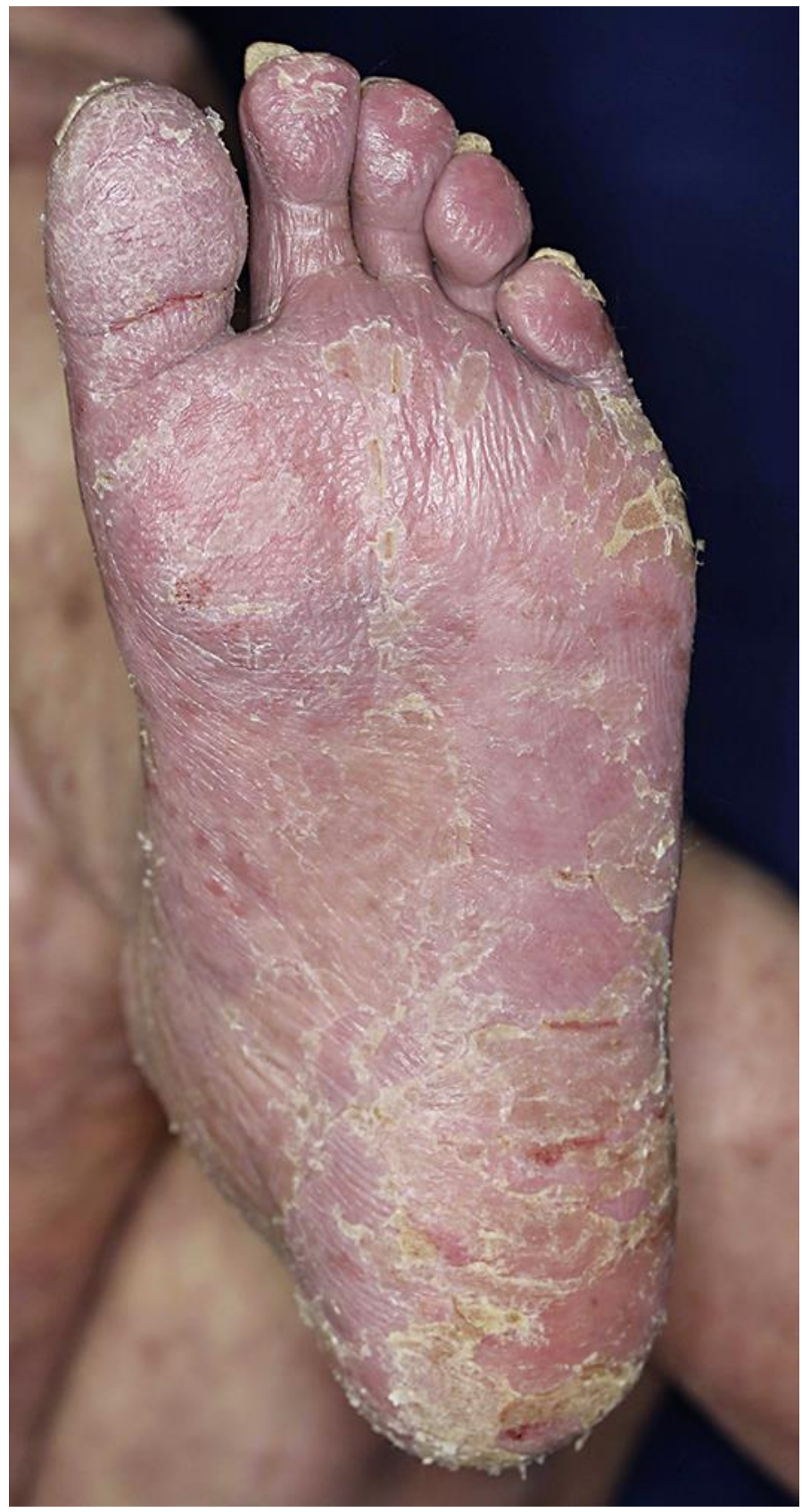

Fig. 1. Clinical appearance during the first visit. Hyperkeratotic erythematous plaque on the left sole. Hyperkeratotic erythematous plaques developed on the bilateral palms and soles. Nails were thickened and fissures were found. Examination using potassium hydroxide on the scales was negative for a fungal infection. 


\section{Case Reports in Dermatology}
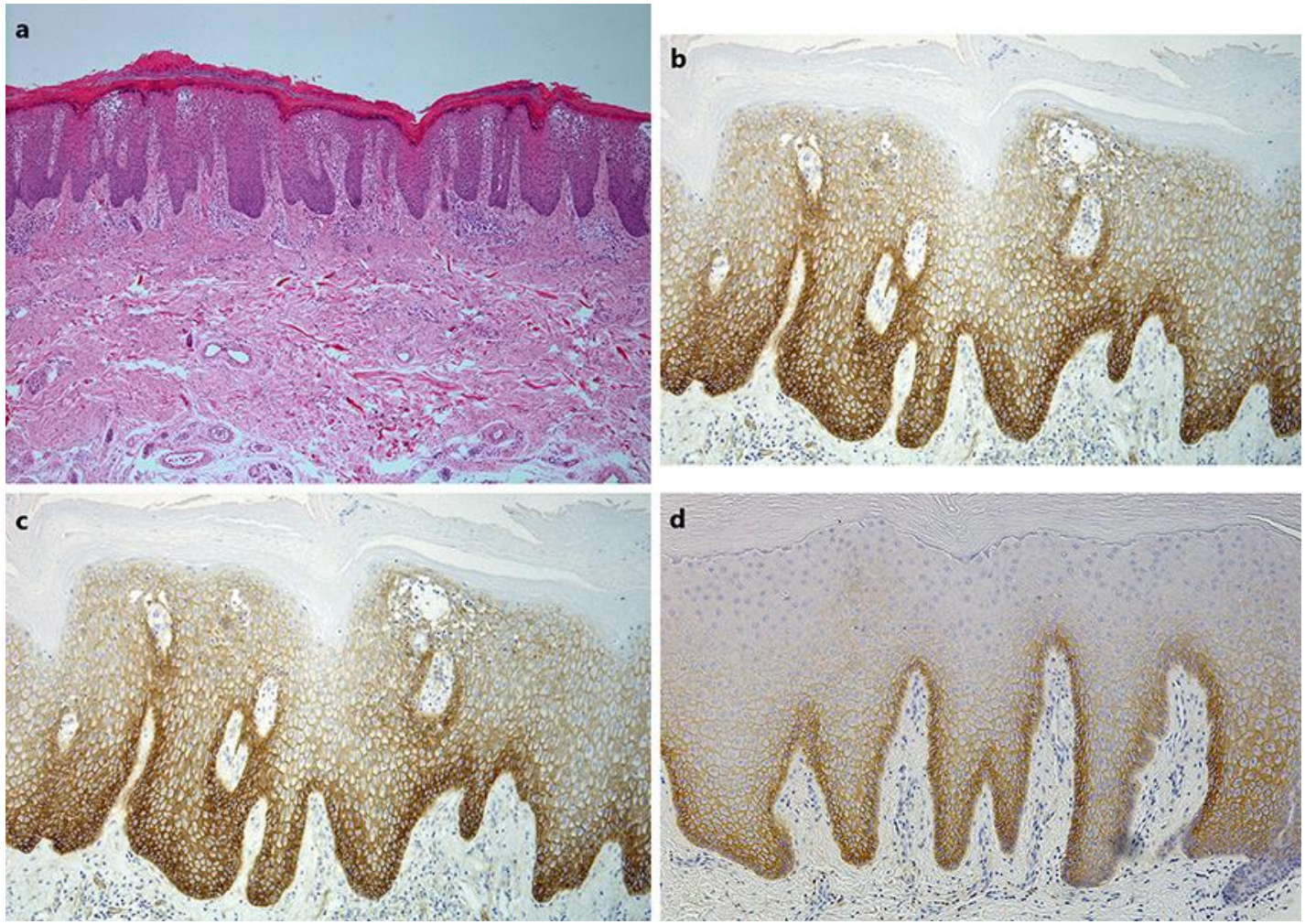

Fig. 2. Histological and immunohistochemical findings during the first visit. a, b Skin biopsy of hyperkeratotic erythema on the left palm. Hematoxylin and eosin staining revealed parakeratosis, acanthosis, elongated rete ridges, and perivascular lymphocyte infiltration of the upper dermis. The granular layer did not disappear and exocytosis of lymphocytes was found. Original magnifications: $\times 40$ (a) and $\times 100$ (b). c, d Immunohistochemical staining with EGFR of hyperkeratotic erythema on the left palm 2 weeks (c) and on the left sole 4 weeks (d) after lobectomy for lung cancer. Lesional keratinocytes highly expressed EGFR 2 weeks after surgery, and its expression was decreased 4 weeks after surgery. Original magnifications: $\times 100($ c) and $\times 100($ d). 